\title{
Five years of complete remission of gastric diffuse large B cell lymphoma after eradication of Helicobacter pylori infection
}

\author{
M M Alsolaiman, G Bakis, T Nazeer, R P MacDermott, J A Balint
}

Long term follow up data are not available for cases of diffuse large B cell gastric lymphoma treated by eradicating Helicobacter pylori alone. We present the case of an 82 year old man with diffuse large B cell lymphoma localised to the stomach which responded to $H$ pylori eradication and which has not recurred after more than five years of close follow up. Our patient was not a candidate for other modalities of treatment. This case demonstrates that the option of treating $\mathrm{H}$ pylori infection as the initial trial of treatment for localised diffuse large B cell lymphoma is appropriate for consideration. If medical therapy using eradication of $\mathrm{H}$ pylori is used, it is essential that the patient undergoes close observation and repeated surveillance endoscopies.

$\mathrm{H}$ elicobacter pylori is a potent immunological stimulus ${ }^{1}$ and recently there has been strong epidemiological and histological evidence to classify $H$ pylori as a definite carcinogen. ${ }^{3}$ It has been postulated that extranodal marginal zone B cell lymphoma of mucosa associated lymphoid tissue (MALT lymphoma) is a result of genetic changes that occur within the B cells of the MALT secondary to stimulation by $H$ pylori organisms. ${ }^{25}$ These lymphomas exhibit low grade histology. There is a close association between gastric lymphoma and $H$ pylori infection, which is seen in $72-98 \%$ of low grade MALT lymphomas and in $38-51 \%$ of diffuse large B cell lymphomas ${ }^{67}$ (previously called high grade MALT lymphoma). ${ }^{8}$ It has been shown in a prospective multicentre study and many case reports that remission of low grade gastric MALT lymphoma can be achieved by eradication of $H$ pylori alone. ${ }^{7-11}$ Primary diffuse large $\mathrm{B}$ cell lymphomas of the stomach are not considered treatable with antimicrobial agents alone. ${ }^{6}{ }^{12}{ }^{13}$ We report the case of a patient with diffuse large B cell lymphoma which resolved completely following eradication of $\mathrm{H}$ pylori, with no residual disease found over 5.5 years of careful endoscopic and biopsy follow up.

\section{CASE REPORT}

An 82 year old Caucasian male was referred to our department with a four month history of postprandial abdominal pain associated with a recent weight loss of five pounds. There was no prior history of peptic ulcer disease. His past medical history was significant for unstable coronary artery disease and coronary artery bypass surgery. The patient underwent oesophagogastroduodenoscopy that revealed a $3 \times 3 \mathrm{~cm}$ ulcer at the angularis (fig 1). In biopsies from this area, the gastric mucosa was diffusely infiltrated by a population of large atypical lymphoid cells (fig 2). The lymphoid nature of these cells was confirmed by positive immunohistochemical staining for CD45 (leucocyte common antigen). CD20 (L26)

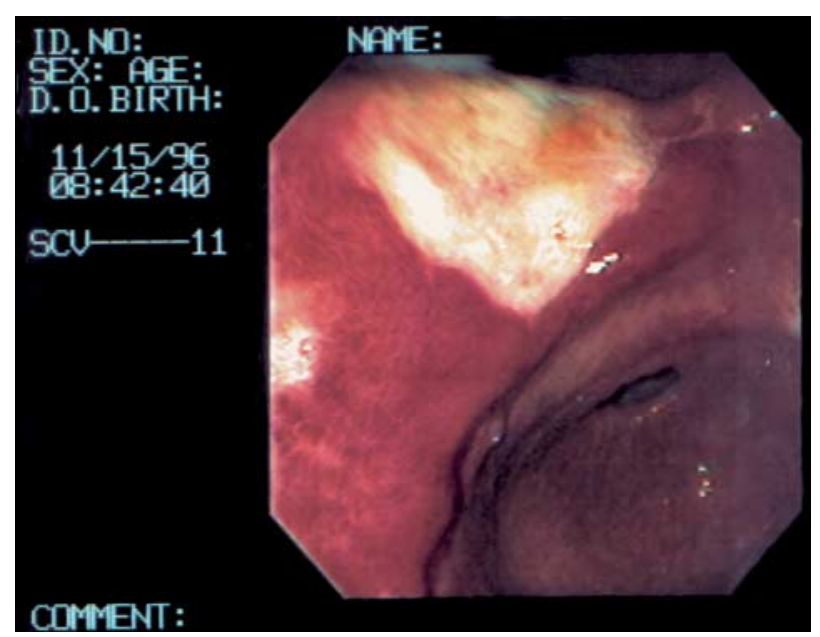

Figure 1 Oesophagogastroduodenoscopy showing $3 \times 3 \mathrm{~cm}$ ulcer at the angularis.

strongly stained the tumour cells, confirming their B cell lineage. Tumour cells were negative for cytokeratins and CD45RO. This confirmed the diagnosis of diffuse large B cell lymphoma. There was no evidence of a low grade MALT lymphoma. Evidence of chronic $H$ pylori gastritis was present in the adjacent mucosa. Biopsies obtained from other areas of the stomach did not show evidence of lymphoma. Appropriate investigations to stage the lymphoma and exclude the presence of coeliac disease or inflammatory bowel disease as a precursor to the diffuse large B cell lymphoma were performed. Small bowel follow through, small bowel biopsy, and colonoscopy were normal. Bilateral bone marrow biopsy with aspiration and computed tomography (CT) scan of the thorax, abdomen, and pelvis were normal without evidence of lymphadenopathy, splenomegaly, or pulmonary infiltrate. The tumour was staged as stage $\mathrm{I}_{\mathrm{E}}$. Endoscopic ultrasonography (EUS) was not performed on diagnosis as this technique was not available at that time in our institution.

Because of his age and his cardiac status, the patient did not wish to have chemotherapy, radiotherapy, or gastric surgery and preferred to undergo a trial of $H$ pylori eradication treatment with careful follow up. He was treated with lanzoprazole $30 \mathrm{mg}$ twice daily, clarithromycin $500 \mathrm{mg}$ twice daily, and metronidazole $500 \mathrm{mg}$ twice daily for four weeks, with complete resolution of his symptoms. He has continued on lanzoperazole $30 \mathrm{mg}$ once daily since that time.

Abbreviations: MALT, mucosa associated lymphoid tissue; $C T$, computed tomography; EUS, endoscopic ultrasonography. 


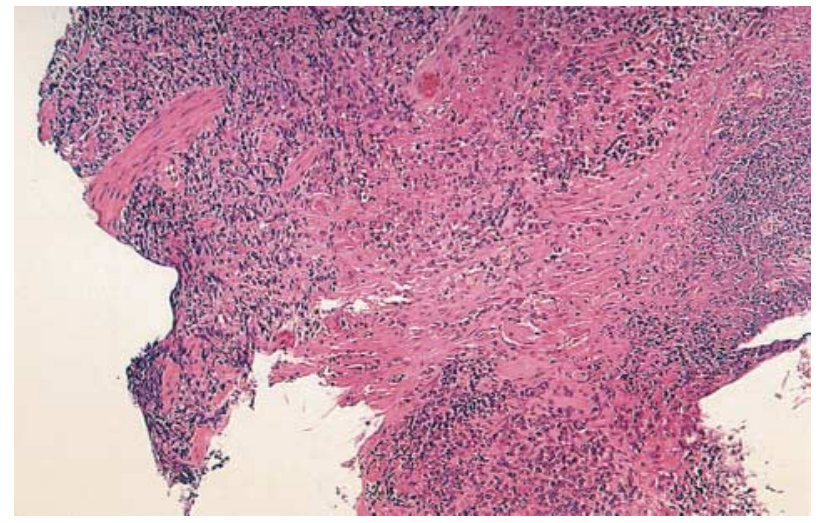

Figure 2 Low power view showing dense lymphoid infiltrate in the gastric wall $(\times 100)$.

Follow up endoscopy two months after initiation of therapy revealed a healing ulcer. In biopsies from this site six months and one year later, there was no residual large cell lymphoma nor $H$ pylori gastritis. The patient reported complete resolution of his symptoms. Over the past 5.5 years the patient has undergone annual oesophagogastroduodenoscopy with multiple mapping biopsies taken at each occasion. Neither lymphoma nor $H$ pylori gastritis have been detected at anytime in the follow up biopsies. Annual abdominal CT scan has also been negative for evidence of recurrent lymphoma.

\section{DISCUSSION}

The role of chronic $H$ pylori infection in the pathogenesis of gastric lymphoma was initially proposed by Wotherspoon and colleagues ${ }^{14}$ when they demonstrated the presence of $H$ pylori infection in $92 \%$ of patients with primary low grade gastric MALT lymphoma. Since then, several lines of evidence have indicated that the development and growth of gastric B cell MALT lymphoma depends on the immunological stimulus provided by $H$ pylori. ${ }^{12}$

There is a clear distinction between diffuse large B cell lymphoma and low grade gastric MALT lymphoma in both their histological and cytological grades as well as their clinical aggressiveness. Low grade MALT lymphomas are composed of small cells with scant cytoplasm and dense nuclear chromatin, ${ }^{48}$ marginal zone cells with moderate amounts of clear cytoplasm, lymphoepithelial lesions, and colonised follicles are often seen. Additionally, plasma cells are frequently seen and are part of the neoplastic clone in one third of cases. $^{8}$ In contrast, diffuse large B cell lymphomas are composed of confluent sheets of large transformed cells with abundant cytoplasm, vesicular nuclei, and prominent nucleoli, ${ }^{45}$ as was seen in our case (fig 3 ).

Low grade MALT lymphomas may transform to diffuse large cell disease. Large cell transformation is a clinically important event and represents a significant adverse change in prognosis. Some studies have shown that large B cell lymphoma may be resistant to treatment using $H$ pylori eradication and that only surgical or chemotherapeutic treatment should be used. ${ }^{1016}$

Although eradication of $H$ pylori infection is effective in treating low grade gastric MALT lymphomas in approximately $75 \%$ of cases, ${ }^{79}$ there are only a small number of cases demonstrating that diffuse large $\mathrm{B}$ cell lymphomas might also respond to eradication therapy. In a prospective study by Chen and colleagues, ${ }^{15}$ they reported complete histological remission of $62.5 \%$ of stage $\mathrm{I}_{\mathrm{E}}$ diffuse large $\mathrm{B}$ cell lymphomas of the stomach following $H$ pylori eradication. The median duration of complete response in their study was 31.2 months. Many of their cases had mixed small and large cell lymphoma. ${ }^{15}$ Morgner et al reported a study of eight patients with diffuse

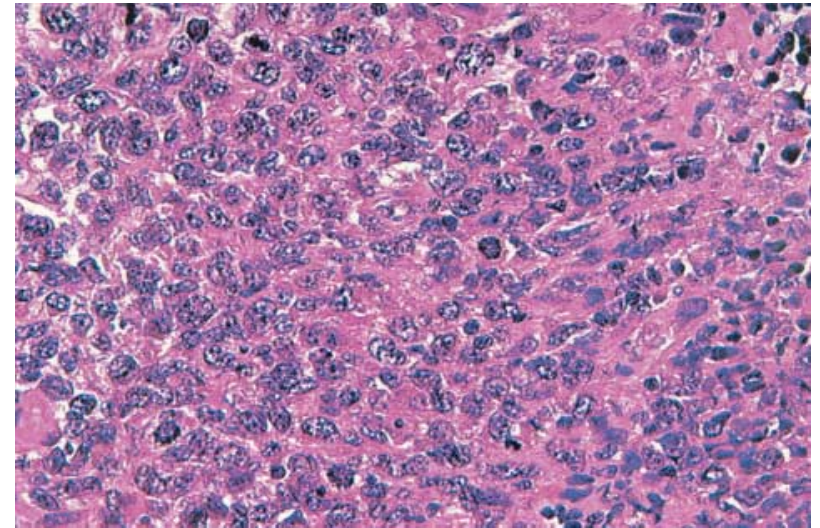

Figure 3 High power view showing confluent sheet of large cells with vesicular nuclei and high mitotic activity $(\times 400)$.

large B cell lymphoma in four of whom complete remission was achieved by eradication of $H$ pylori infection alone. One achieved partial remission. The other three patients underwent further therapy which included chemotherapy in one, surgery in another, and both surgery and chemotherapy in the last. ${ }^{4}$ Gomollon et al reported two cases of localised diffuse large B cell lymphoma that entered remission following treatment for $H$ pylori infection. ${ }^{13}$ Very little data exist on the long term stability of these remissions. On reviewing the current literature, only one case of diffuse large B cell lymphoma has remained in remission after five years of follow up after $H$ pylori eradication alone. ${ }^{4}$ Our patient had no evidence of relapse after 5.5 years of follow up.

It is important to differentiate between patients who may benefit from $H$ pylori eradication as a single modality of treatment and patients who require conventional chemotherapy. ${ }^{10}$ Although some patients with diffuse large B cell lymphoma might benefit from eradication treatment, this should not be considered standard therapy at present. Most of the current literature recommends more aggressive treatment for diffuse large B cell lymphoma because this malignancy can be potentially aggressive. ${ }^{4610}{ }^{16}$ Our case demonstrated that eradication of $H$ pylori infection as the initial approach to treating diffuse large $\mathrm{B}$ cell lymphoma localised to the stomach could be considered in specific situations such as patients refusing surgery, radiotherapy, or chemotherapy, or elderly patients with underlying medical conditions as in our patient.

If $H$ pylori eradication is used as the sole therapy for gastric diffuse large $\mathrm{B}$ cell lymphoma of the stomach then the patient must be willing to undergo close observation with upper endoscopies and multiple biopsies every 3-6 months initially and then every 6-12 months. It would also be important to rule out distant metastases or deep infiltration using CT scan and EUS for staging. EUS has been reported recently in staging gastric and duodenal lymphomas before therapy and in evaluating regression of these tumours after eradication of $H$ pylori. ${ }^{17}{ }^{18}$ Long term follow up of responders is obligatory to establish the efficacy of treatment aimed at $H$ pylori alone in the treatment of gastric diffuse large B cell lymphoma.

\section{ACKNOWLEDGEMENT}

This paper was supported in part by the Albert M Yunich, MD scholarship fund.

\section{Authors' affiliations}

M M Alsolaiman, G Bakis, R P MacDermott, J A Balint, Division of Gastroenterology, Albany Medical College, Albany, New York, USA T Nazeer, Department of Medicine and Department of Pathology, Albany Medical College, Albany, New York, USA 
Correspondence to: Dr M Alsolaiman, Gastroenterology Division, 47 New Scotland Ave MC\# 48, Albany, NY 12208, USA; modar9@hotmail.com

Accepted for publication: 25 June 2002

\section{REFERENCES}

1 Weber DM, Dimopoulos MA, Anadu DP, et al. Regression of gastric lymphoma of mucosa-associated lymphoid tissue with antibiotic therapy for Helicobacter pylori. Gastroenterology 1994;107:1835-8.

2 Hussell T Isaacson PG, Crabtree JE, et al. Helicobacter pylori specific tumor-infiltrating T-cells provide contact dependent help for the growth of malignant $B$ cells in low-grade gastric lymphoma of mucosa-associated lymphoid tissue. J Pathol 1996;178:122-7

3 Uemura N, Okamoto S, Yamamoto S, et al. Helicobacter pylori infection and the development of gastric cancer. 2001;345:784-9.

4 Morgner A, Miehlke S, Fisbach, et al. Complete remission of primary high-grade B-cell gastric lymphoma after cure of Helicobacter pylori infection. J Clin Oncol 2001;19:2041-8.

5 Isaacson PG. Gastric MALT Lymphoma: From concept to cure. Ann Oncol 1999; 10:637-45

6 Boot $\mathbf{H}$, de Jong $D$, Van Heerde $P$, et al. Role of Helicobacter pylori eradication in high-grade MALT lymphoma. Lancet 1995:346:448-9.

7 Bouzourene H, Haefliger T, Delacretaz F, et al. The role of Helicobacter pylori in primary gastric MALT lymphoma. Histopathology $999 \cdot 34: 118-23$

8 Issacson PG, Muler-Hermelink HK, Piris MA, et al. Extranodal marginal zone B-cell lymphoma of mucosa associated lymphoid tissue (MALT lymphoma). In: Jaffe ES, Harris NL, Stein H, et al. World Health Organization Classification of Tumors. Pathology and Genetics of Tumors of Hematopoietic and Lymphoid Tissues. Lyon: IARC Press, 2001:157-60.
9 Fischbach W, Dragosics B, Kolve-Goebler, et al. Prinary gastric B-cell lymphoma: results of a prospective multicenter study. Gastroenterology 2000;119:1191-202.

10 Thiede C, Morgner A, Alpen B, et al. What role does Helicobacter pylori eradication play in gastric MALT and gastric MALT lymphoma? Gastroenterology 1997;113:S61-4.

11 Steinbach G, Ford R, Golber G et al Antibiotic treatment of gastric lymphoma of mucosa-associated lymphoid tissue: An uncontrolled study. Ann Intern Med 1999;131:88-95.

$12 \mathrm{Ng} \mathrm{W-W}$, Lam C-P, Chau W-K, et al. Regression of high-grade gastric mucosa- associated lymphoid tissue lymphoma with Helicobacter pylori after triple antibiotic therapy. Gastrointest Endosc 2000;51:93-6.

13 Gomollon F, Yus C, Uribarrena, R, et al. High-grade gastric MALT lymphoma: regression after cure of helicobacter pylori infection. AGA abstracts. Gastroenterology 1996;110:A120.

14 Wotherspoon AC, Ortiz-Hidalgo C, Falzon MR, et al. Helicobacter pylori associated gastritis and primary B-cell gastric lymphoma. Lancet 1991;338:1175-6.

15 Chen LT, Lin JT, Shyu RY, et al. Prospective study of Helicobacter pylori eradication therapy in stage $I_{E}$ high-grade mucosa-associated lymphoid tissue lymphoma of the stomach. J Clin Oncol 2001;19:4245-51.

16 Hussell T, Isaacson PG, Crabtree JE, et al. The response of cells from low-grade B-cell gastric lymphoma of mucosa-associated lymphoid tissue to Helicobacter pylori. Lancet 1993;342:571-4.

17 Nakamura S, Matsumoto T, Nakamura S, et al. Duodenal mucosa-associated lymphoid tissue lymphoma treated by eradication of Helicobacter pylori: Report of 2 cases including EUS findings. Gastrointest Endosc 2001;54:772-5.

18 Nakamura S, Matsumoto T, Suekane H, et al. Predictive value of endoscopic ultrasonography for regression of gastic low grade and high grade MALT lymphomas after eradication of Helicobacter pylori. Gut $2001 ; 48: 454-60$ 